\title{
SLEEP APNEA WORST SLEEP QUALITY IN THE ELDERLY AT THE OUTPATIENT CLINIC OF Dr. SOETOMO HOSPITAL SURABAYA AND AIRLANGGA UNIVERSITY HOSPITAL SURABAYA
}

\author{
Edfina Rahmarini ${ }^{1,2,3}$, Wardah Rahmatul Islamiyah ${ }^{2,3,4}$, Muhammad Hamdan ${ }^{2,3}$ \\ ${ }^{1}$ Neurology Resident, Faculty of Medicine, Universitas Airlangga \\ ${ }^{2}$ Department of Neurology, Faculty of Medicine, Universitas Airlangga \\ ${ }^{3}$ Dr. Soetomo General Hospital \\ ${ }^{4}$ Universitas Airlangga General Hospital
}

\section{Corresponding Author:}

Wardah Rahmatul Islamiyah, dr. Sp.N (K)

Department of Neurology, Faculty of Medicine, Universitas Airlangga, Surabaya, Indonesia

Jalan Mayjen Prof. Dr. Moestopo 47, Surabaya, Indonesia

Email: wardah-r-i@fk.unair.ac.id

\begin{abstract}
Background: Sleep disorders often occur in the elderly, Sleep Apnea often occurs in the elderly. Sleep disorders worsen the quality of life of the elderly and reduce the productivity of the elderly

Objective: The purpose of this study was to determine the relationship between sleep apnea and sleep quality in the elderly

Methods: This study is a cross-sectional study conducted in a multicenter manner at the outpatient polyclinic of RSUD Dr. Soetomo and the outpatient polyclinic at the Airlangga University Hospital, Surabaya. Each subject who entered this study will fill out the SDQ questionnaire to measure sleep apnea and the PSQI questionnaire. This study was approved by the ethics committee of RSUD Dr. Soetomo Surabaya and Airlangga University Hospital Surabaya from Dr. Sutomo Hospital number 0249/KEPK/VIII/2021 and from Universitas Airlangga Hospital number 170/KEP/2021.

Results: We collected data from 345 patients who were treated at the outpatient polyclinic of Dr. Soetomo Hospital Surabaya and Airlangga University Hospital Surabaya. It was found that 24 patients (7\%) were in the sleep apnea category and 321 patients (93\%) were not in the sleep apnea category. Of the 24 patients with sleep apnea category, 22 patients had sleep disturbances as measured by the PSQI questionnaire $(91.7 \%)$ and 2 patients (no sleep disturbances) this was statistically significant $\mathrm{p}<0.01$; OR 44.17(CI 95\%)(10.124192.729)

Conclusion: Sleep apnea has an influence on sleep quality in the elderly in the outpatient polyclinic of RSUD Dr. Soetomo and Airlangga University Hospital Surabaya
\end{abstract}

Keywords: Sleep Apnea, Sleep Quality, Elderly 


\section{Introduction}

The sleep disorders are associated with health and mortality, and not only affect the person but also the family and the whole society. ${ }^{1}$ The quality of life and activity of people during waking hours is greatly influenced by their quality of sleep. ${ }^{1}$ Many sleep disorders are considered life threatening. Elderly Sleep disorders are very common in the elderly with an average prevalence of up to $50 \%$. The average incidence of sleep disorders is estimated at 3-5 percent. . ${ }^{2}$ Sleep apnea affects sleep quality, especially in patients with chronic diseases. ${ }^{3}$ Poor sleep quality can have an impact on worsening a person's quality of life. ${ }^{4}$ Specific symptoms of sleep disturbance were: difficulties falling asleep, repeated awakenings with difficulties falling asleep again (hereafter "difficulties maintaining sleep"), premature final awakening (hereafter "premature awakening") and disturbed or restless sleep (hereafter "restless sleep"). Sleep disturbance was obtained by the mean score of these four items. ${ }^{5}$ This study was conducted to determine the relationship between sleep apnea and sleep quality in the elderly .

\section{Methods}

This research is a cross sectional study. Subjects were taken by taking from every patient who came for control to the outpatient polyclinic of RSUD Dr. Soetomo and RS Universitas Airlangga Surabaya from September to November 2021 by consecutive sampling. The inclusion criteria of this study are male or female aged more than 60 years, can speak Indonesian, read, write. Exclusion criteria from this study were patients who consumed drugs, sleeping pills, sedatives, patients who had cognitive disorders, aphasia. This study uses the PSQI questionnaire which has been validated in Indonesian by Alim in $2015^{6}$ and uses the Sleep disorder questionnaire which has been validated in the Indonesian version noted on the sleep perdossi book. Sociodemographic factors (Age, Gender, Body Mass Index) will be considered. All data collected were analyzed using spss 28.

\section{Results}

We collected 345 participants from the outpatient polyclinic of RSUD Dr. Sutomo and Airlangga University Hospital Surabaya. We identified 345 patients who met the inclusion and exclusion criteria. Of the 345 participants, 201 were male and 104 were female. The average BMI of patients in this study was 24.61+4.09 The minimum BMI value in this study was 15.40, the maximum BMI value in this study was 38.30. The age of participants in this study had a mean value of 66.92, a maximum value of 87 and a minimum value of 60 with a standard deviation $+5,377$ it can be seen from table 1 .

We got data. The results of a bivariate analysis of the relationship between Sleep Apnea as assessed by SDQ and sleep disturbances assessed by PSQI found that 22 of the 24 subjects with sleep apnea (91.7\%) had sleep apnea and in the non-sleep apnea category who had sleep disturbances were 64 out of 257 of the subjects (19.9), however this was statistically significant with $\mathrm{p}<0.01$. This can be seen in table 2 .

We got data on all research subjects $(n=345)$, none of them had circadian rhythm disorders, none had movement disorders, or parasomnia disorders. Meanwhile, the number of subjects who did not experience circadian rhythm disturbances but had sleep disorders were $86(24.9 \%)$ subjects, the number of subjects who did not experience movement disorders but had sleep disturbances was 86 (24.9\%) subjects, the number of subjects who did not experience parasomnias but experiencing sleep disturbances were $86(24.9 \%)$. This can be seen in tables 4,5 and 6 .

We got data on all research subjects $(n=345), 6(100 \%)$ subjects got Psychiatric problem and experience sleep disorder $0(0 \%)$ subject got psikiatric problem without sleep disorder, 259(76.4\%) subjects didn't experience sleep disorder without psychiatric problem and 80(23.6\%) Subject without psychiatric problem but experience sleep disorder. This can be seen in table7. 
Table 1. Demographic and Clinical Data

\begin{tabular}{lccc}
\hline Population & n(\%) & value & SD \\
\hline Sex & $201(58.3)$ & & \\
Male & $144(41.7)$ & & \\
Female & & & \pm 4.09 \\
BMI & & 24.61 & \\
Mean & & 15.40 & \\
Minimum & 38.30 & \pm 5.377 \\
Maksimum & & \\
Age & & 66.92 & \\
Mean & & 60 & \\
Minimum & & & \\
Maksimum & & & \\
\hline
\end{tabular}

Table 2 Correlation Sleep Apnea with Sleep Quality

\begin{tabular}{|c|c|c|c|c|c|}
\hline & \multicolumn{2}{|c|}{ PSQI } & \multirow{2}{*}{$\begin{array}{c}\text { Total } \\
(\%)\end{array}$} & \multirow[b]{2}{*}{$\mathrm{p}$} & \multirow[b]{2}{*}{$\begin{array}{l}\text { CI } 95 \% \\
\text { OR }\end{array}$} \\
\hline & $\begin{array}{c}\text { No Sleep } \\
\text { disturbance } \\
(\%)\end{array}$ & $\begin{array}{c}\text { Sleep } \\
\text { Disturbance } \\
(\%)\end{array}$ & & & \\
\hline \multicolumn{6}{|c|}{ Sleep Apnea } \\
\hline Yes & $2(8.3)$ & $22(91.7)$ & (100) & \multirow[t]{2}{*}{$<0.01$} & 44.172 \\
\hline No & $257(80.1)$ & $64(19.9 \%)$ & $(100)$ & & $\begin{array}{l}\text { Upper } \\
192.729\end{array}$ \\
\hline Total & 259 & 86 & & & $\begin{array}{l}\text { Lower } \\
10.124\end{array}$ \\
\hline
\end{tabular}


Table 3. Sirkadian Rhytm Disturbance and PSQI

\begin{tabular}{lccc}
\hline Sirkadian Rhytm & \multicolumn{2}{c}{ PSQI } & $\begin{array}{c}\text { Total } \\
\text { Disturbance }\end{array}$ \\
\cline { 2 - 3 } & $\begin{array}{c}\text { No Sleep disturbance } \\
(\%)\end{array}$ & $\begin{array}{c}\text { Sleep } \\
\text { Disturbance (\%) }\end{array}$ & \\
\hline & & \\
Yes & $0(0)$ & $0(0)$ & $(0)$ \\
No & $259(75.1 \%)$ & $86(24.9 \%)$ & $(100)$ \\
\hline Total & 259 & 86 & \\
\hline
\end{tabular}

Table 4. Movement Disorder disturbances and PSQI

\begin{tabular}{|c|c|c|c|}
\hline \multirow{2}{*}{$\begin{array}{l}\text { Movement } \\
\text { Disorder } \\
\text { disturbances }\end{array}$} & \multicolumn{2}{|c|}{ PSQI } & \multirow{2}{*}{$\begin{array}{l}\text { Total } \\
(\%)\end{array}$} \\
\hline & $\begin{array}{c}\text { No Sleep disturbance } \\
(\%)\end{array}$ & $\begin{array}{c}\text { Sleep } \\
\text { Disturbance }(\%)\end{array}$ & \\
\hline Yes & $0(0)$ & $0(0)$ & $(0)$ \\
\hline No & $259(75.1 \%)$ & $86(24.9 \%)$ & $(100)$ \\
\hline Total & 259 & 86 & \\
\hline
\end{tabular}

Table 5. Parasomnia and PSQI

\begin{tabular}{lccc}
\hline Parasomnia & \multicolumn{2}{c}{ PSQI } & $\begin{array}{c}\text { Total } \\
(\%)\end{array}$ \\
\cline { 2 - 4 } & $\begin{array}{c}\text { No Sleep disturbance } \\
(\%)\end{array}$ & $\begin{array}{c}\text { Sleep } \\
\text { Disturbance }(\%)\end{array}$ & $(0)$ \\
Yes & $0(0)$ & $0(0)$ & $(100)$ \\
No & $259(75.1 \%)$ & $86(24.9 \%)$ & \\
\hline Total & 259 & 86 & \\
\hline
\end{tabular}


Table 6 Psychiatric Problem and PSQI

\begin{tabular}{lccc}
\hline Psychiatric Problem & \multicolumn{2}{c}{ PSQI } & $\begin{array}{c}\text { Total } \\
\end{array}$ \\
\cline { 2 - 3 } & $\begin{array}{c}\text { No Sleep disturbance } \\
(\%)\end{array}$ & $\begin{array}{c}\text { Sleep } \\
\text { Disturbance }(\%)\end{array}$ & \\
\hline Yes & $0(0)$ & $0(0)$ & $(0)$ \\
No & $259(75.1 \%)$ & $86(24.9 \%)$ & $(100)$ \\
\hline Total & 259 & 86 & \\
\hline
\end{tabular}

\section{Discussion}

In this study, sleep apnea was statistically significant in influencing sleep quality, $\mathrm{p}<0.01$. This is in accordance with the research of S. Bajaj, et al $2015^{3}$ which states that sleep apnea can worsen a person's sleep quality. Both of these studies have the same results because both of these studies have the same results, most of the patients with chronic diseases in this study have sleep disorders. Their data demonstrates the complex relationship between OSA and cirrhosis with respect to cognitive function, sleep quality and driving simulator performance. We found that OSA and cirrhosis affect cognition, sleep and driving differently and correction of underlying OSA using CPAP in cirrhotic patients can modulate the sleep quality, driving simulation (i.e., lane deviation errors) and executive function (i.e., number of lures). Impaired sleep quality and daytime sleepiness were higher in OSA groups, with no additive impact of cirrhosis.

In this study, most of the patients with sleep apnea measured by the SDQ (Sleep Disorder Questionnaire) also experienced sleep disturbances as measured by the PSQI (Pittsburg Sleep Questionnaire Index). This was also found in the study of Sameera, et al in 2017. ${ }^{1}$ In the sameera study, the undesirable sleep quality and few numbers of obstructive sleep apnea and sleepiness during the day were observed in the drivers. The study performed in Darab on the drivers showed that the sleep quality of $40 \%$ of the truck drivers based on $5 \%$ cut-off point was undesirable. There was also a significant correlation between working shifts with PSQI, ESS, and Stop Bang. Meaning that number of people in the evening and night working shifts had significant relationship with the mean scores for the three questionnaires. the mean score of ESS and Stop Bang questionnaires had a significant relationship with the history of pulmonary disease. Examining the history of the disease in drivers have shown that they had the heart and respiratory diseases rarely, surgical history and orthopedic problems and the majority were healthy enough for occupational activity ${ }^{1}$.

This study has a problem, Not all outpatient clinics can be sampled properly due to the limitations of the research team members, however the results of data analysis show that it is statistically significant $\mathrm{p}<0.01$ OR 44.17 (95\% CI) (10.124-192.729) sleep apnea affects a person's sleep quality.

Peristera Reaearch 2021 showed that average trends hide distinctive patterns of change at retirement. Most participants experienced moderate reductions in sleep difficulties, a minority experienced relatively large reductions, and another minority little or no reduction at all. Those with low levels of sleep disturbance before retirement tended to be much less affected or were unaffected by the retirement transition, a finding that would be lost if only examining average trends. ${ }^{5}$

These findings have implications for policy and practice, indicating that retirement has differential effects such that those experiencing greatest pre-retirement sleep difficulties benefit most. Policies aiming to raise average age of retirement by increasing age of eligibility for state pensions typically apply the same pensionable age across the board. These extended working lives policies may accentuate inequalities in sleep quality by lengthening the period when those with poor sleep experience work-related sleep difficulties while having little impact on the sleep of those who experience few sleep difficulties. As reduced sleeping problems at retirement may lie behind the widely observed trend of 
improved mental health after retirement. ${ }^{5}$

It is unfortunate that the results on the variables of circadian rhythm disorders, parasomnias, movement disorders in this study did not get results for subjects who had circadian rhythm disorders, parasomnias, movement disorders so that sleep disorders in these three variables could not be analyzed.

The psychiatric problem in this study cannot be analyzed because there is one part of the chisquare table with a value of zero. This is unfortunately different from the 1989 Buysse study which stated that psychiatric disorders can affect a person's sleep quality. ${ }^{8}$ Buysse research was claimed Age was a significant covariate only for the daytime dysfunction component; but contrary to expectations, these factors were inversely correlated, i.e., reported severity of daytime dysfunction tended to be greater in younger than in older subjects. Sex was a significant covariate for use of sleeping medications and habitual sleep efficiency, with males showing higher scores for each of these components. Age and sex were both significant covariates for the PSQ1 global score, but group differences were highly statistically significant even after covarying for these factors. ${ }^{8}$

The PSQl's simplicity and its ability to identify different groups of patients suggest several clinical and research applications in psychiatry and general medical settings. Most fundamentally, it may be used as a simple screening measure to identify cases and controls, or "good" and "poor" sleepers. In a general clinical setting, the PSQI could be used to screen patients for the presence of significant sleep disturbance. In psychiatric settings, the PSQI may identify patients who are likely to have a sleep disturbance concomitant with their psychiatric symptoms. In addition, it may direct the clinican to specific areas of dysfunction that require further investigation. The PSQI could also be used in clinical research and epidemiological studies to identify groups that differ in the quality of their sleep. The PSQI may also have several longitudinal applications in clinical practice and research. ${ }^{8}$

This study has a drawback that all methods of measuring variables using a questionnaire that relies on the memory of the subject. To confirm each variable, it is necessary to confirm with more objective tool, namely polysomnography or actigraph. Penelitian yang dilakukan

\section{CONCLUSION}

Sleep apnea has an influence on sleep quality in the elderly in the outpatient polyclinic of RSUD Dr. Soetomo and Airlangga University Hospital Surabaya

\section{ACKNOWLEDGMENTS}

Gratitude is due to the Director and Head of Neurology Department, Head of Sleep Division, Head of Neurogeriatry DR Soetomo General Hospital, and Airlangga University Hospital Surabaya East Java, Indonesia.

\section{AUTHOR CONTRIBUTIONS}

All authors have accepted responsibility for the entire content of this manuscript and approved its submission.

\section{COMPETING INTERESTS}

The authors state no conflict of interest.

\section{STATEMENT OF ETHICS}

This research has received a letter of ethics from Dr. Sutomo Hospital number 0249/KEPK/VIII/2021 and from Airlangga University Hospital number 170/KEP/2021. This paper Never been published in the other journal and wouldn't be published in other journal. 


\section{REFERENCE}

1. Motlagh SJ, Shabany M, Haghighi KS, Nasrabadi AN, Razavi SHE. Relationship between sleep quality, obstructive sleep apnea and sleepiness during day with related factors in professional drivers. Acta Med Iran. 2017;55(11):690-5.

2. Miner B, Kryger MH. Sleep in the Aging Population. Sleep Med Clin [Internet]. 2017;12(1):31-8. Available from: http://dx.doi.org/10.1016/j.jsmc.2016.10.008

3. Bajaj JS, Thacker LR, Leszczyszyn D, Taylor SA, Heuman DM, Raman S, et al. Effects of obstructive sleep apnea on sleep quality, cognition, and driving performance in patients with cirrhosis. Clin Gastroenterol Hepatol. 2015;13(2):390-397.e1.

4. Lo CMH, Lee PH. Prevalence and impacts of poor sleep on quality of life and associated factors of good sleepers in a sample of older Chinese adults. Health Qual Life Outcomes. 2012;10:1-7.

5. Peristera P, Nyberg A, Magnusson Hanson LL, Westerlund H, Platts LG. How consistently does sleep quality improve at retirement? Prospective analyses with group-based trajectory models. J Sleep Res. 2021;(April):1-15.

6. Alim IZ. Uji Validitas dan Reliabilitas Instrumen Pittsburgh Sleep Quality Index Versi Bahasa Indonesia = Test Validity and Reliability of the Instrument Pittsburgh Sleep Quality Index Indonesia Language Version. Univ Indones [Internet]. 2015;135. Available from:

http://lib.ui.ac.id/hasilcari?query=katakunci: \%22Pittsburgh Sleep Quality Index, penyakit ginjal kronis, kualitas tidur, validitas, reliabilitas.\%22

7. Rahmatul Islamiyah wardah. INSOMNIA. kedua. rahmatul Islamiyah W, editor. Jakarta: Sagung Seto; 2018. 63-115 p.

8. Buysse DJ, Reynolds CF, Monk TH, Berman SR, Kupfer DJ. Buysse DJ, Reynolds CF, Monk TH, Berman SR, Kupfer DJ. The Pittsburgh Sleep Quality Index: a new instrument for psychiatric practice and research. Psychiatry Res. 1989;28:193-213. 1989; 